We have been taught that a responsibility of the editor-compiler is to guide and assist the reader by providing explanation of matters unclear, helpful signposts to the unfamiliar, and references lacking in the original. This responsibility has here been almost wholly disregarded. The quotations on pages 190, 263, 269, and 370 (top), for example, are nowhere identified.

There are, of course, a number of good things in the volume-Raynard Swank's "Sight and Sound in the World of Books," Pierce Butler's "The Bibliographical Function of the Library," and Leon Carnovsky's "The Obligations and Responsibilities of the Librarian Concerning Censorship," to mention just three. There will be very few, the undersigned not among them, who will not find here at least one unfamiliar piece. Yet, the total effort is faulty and seems not worth the labor expended-or the six-dollar price tag by the publisher.

To prove that the book has been carefully read and to imply knowledge it is customary, in a review of this kind, to include a list of errors. No such list is here appended, but it may be suggested that the cause of librarianship, to say nothing of scholarship in general, is ill-served by a volume of this size which contains more than 50 transgressions.

This is not a "representative" compilation in terms of period, nationality, or even kinds of libraries and librarianship. There is nothing, for example, on the university or scholarly library, as such. The work cannot fail to give the neophyte a distorted, incomplete and, at times, a false picture. That the established, well-read librarian will derive much in the way of pleasure or profit seems doubtful.-J. Periam Danton, University of California (Berkeley).

\title{
Book Classification and the Problem of Change: A Reply
}

In general, I agree with David Haykin's "Book Classification and the Problem of Change" (c\&RL, October, 1955). However, if Mr. Haykin did not mean to imply that no changes should be made in the Dewey Classification schedules by individual libraries, he should have expanded his article a little. If a small, general library, for instance, can make its collections more accessible and logical to its users by slight and reasonable deviations from the Dewey schedules, no one should question that it is the practical thing to do.

The Yale Club Library, for one, finds it difficult to use effectively the schedules for Economics of Industry (338.1-338.4). Take, for example, the subject of cotton. The schedules call for four different classifications: under Botany, Culture, Economics of Manufacture, and Economics of Production. Since general books on the subject of cotton in a small library usually cover at least two of these facets, it is better for them to have the subject confined to one class, say 633.5 , with the possible exception of straight botanical works, which it probably won't have anyway.
Our readers will ask where the books on cotton are and it is easy for the librarian to answer 633.5, without going to the catalog, and at the same time knowing that there will at least be one book there. It is easier on the reader, too, who usually prefers to avoid the catalog if he can, and who certainly always prefers not to have to chase around the classification to find books that to him and to the librarian logically belong in one place. The same holds true, more or less, for coffee and any number of other products or subjects.

Mr. Haykin did not make it clear that there is a difference between the intention of the editors of the Dewey Decimal Classification and the classifiers on a library's staff. While it is true that all classifiers will agree on the class for most books, many classifiers will disagree on the class of many books, regardless of the editors' intentions.

Many small libraries classify their books before they obtain the LC cards. Usually they arrive at the same class as the Dewey classifiers at LC, but sometimes they do not. It is possible that the LC classifiers are a little too theoretical in this respect. They do not always succeed in checking back to 
see how they had previously classified a hard-to-classify book on almost exactly the same subject as the one in hand. Even though the original decision or a later revised decision on a class number is a controversial one, they should be consistent about it eventually and not leave it to the discretion of the individual classifier on the library's staff. Perhaps they are sometimes thrown off the track by the fact that they may work on the book after somewhat inconsistent subject headings have been supplied by others.

Too complete theory, coupled with human frailty, will not give us the conformitv Mr. Haykin, and indeed all librarians, would like to advocate.-Joseph W. Roberts, Librarian, Yale Club of New York City.

\section{Nominees for ACRL Section Offices, 1956-57}

\section{College Libraries Section}

\author{
Vice-Chairman and Chairman-Elect \\ Martha Biggs \\ Sister Marie Inez
}

\section{Secretary \\ Gladys M. Brownell \\ Mrs. Mary Gillen Henley}

Pure and Applied Sciences Section

Vice-Chairman and Chairman-Elect Harlan Brown

Edward A. Chapman

\section{Secretary \\ Harald Ostvold \\ Esther Schlundt}

\section{Reference Librarians Section}
Vice-Chairman and Chairman-Elect Wayne N. Hartwell
Bernard L. Foy

\author{
Secretary \\ Mary Kahler \\ Jean K. Taylor
}

\section{Libraries of Teacher Training \\ Institutions Section \\ Secretary and Chairman-Elect \\ M. Frances Breen \\ E. Walfred Erickson}

\section{University Libraries Section}

Vice-Chairman and Chairman-Elect

Evelyn M. Fritz

Robert H. Muller

\author{
Secretary \\ Margaret E. Knox \\ Samuel Rothstein
}

\section{Study of Education for Librarianship}

Western Reserve University School of Library Science has been given a $\$ 50,000$ grant by the Carnegie Corporation of New York for a study of education for librarianship in America.

Dr. Jesse H. Shera, dean of the WRU library school, has outlined a program of research and experimentation in education of librarians. Evolving from the three-year study under the Carnegie grant will be the foundation for a new curriculum in librarianship at WRU. This and two projected publications are expected to have implications reaching far be- yond the Western Reserve campus. One of the books will discuss education for the library profession in a form designed for professional librarians, particularly directors of library schools. The other will be an introduction to librarianship, designed for beginning students and planned for possible use as a textbook in an elementary survey course.

This year an advanced program in conjunction with the Graduate School of WRU has made it possible for the university to offer the Doctor of Philosophy degree with a major in library science. 